\title{
Um percurso em Porto Alegre: cidade, história e urbanismo
}

\author{
Celia Ferraz de Souza*
}

Resumo: O propósito deste artigo é procurar despertar no leitor uma maneira especial de ver a cidade, através das transformações ocorridas no seu espaço físico ao longo de um percurso. As transformações não são fruto do acaso. Há por trás delas muitas ideias para se discutir. Perceber que a cidade é um objeto plural, com marcas de diversos tempos é ter a convicção de que as obras, que se realizam hoje, podem ser as permanências do futuro. Aqui não se está falando da edificação pura e simples, mas da sua relação com o todo. Como eram as relações no passado e como chegaram ao presente. Relações sociais, culturais, econômicas, políticas, nesse espaço delimitado. Nesse trabalho foi escolhido um percurso em Porto Alegre, do centro histórico à zona sul da cidade, no bairro Vila Assunção, onde se atravessa não só a história da cidade, como a história do urbanismo. Ver a história através do elemento concreto e real permite ao cidadão se apropriar da sua própria cidadania.

Palavras-chave: Urbanismo, Historia da cidade, Cidades brasileiras, Porto Alegre.

\footnotetext{
Arquiteta, Doutora em Arquitetura e Urbanismo, Professora da Faculdade de Arquitetura e do Programa de Pós-Graduação em Planejamento Urbano e Regional, da UFRGS. Autora dos livros Porto Alegre e sua Evolução, Plano de Melhoramentos de Porto Alegre, O plano que orientou a modernização de Porto Alegre, Rio Grande do Sul: Contraste Regionais e Formaçôes Urbanas, entre outros. E-mail: cfrsouza@terra.com. br
} 


\begin{abstract}
The purpose of this paper (or research paper) is to arouse in the reader a special way of seeing the city through the changes occurred in the physical place along the way. The transformations do not happen by chance. There are many ideas behind it. Recognize that the city is a plural object with marks from different eras is to have the conviction that the constructions from today could be those that last in the future. We are not referring to building exclusively, but to its relation with the whole environment: How the relations from the past (social, cultural, economic and political ones) exist in the present time? In this paper, we have chosen a circuit in Porto Alegre: going from its historical center to Vila Assunção borough, in the south of the city. It goes not only through the city, but also through the urbanism's history. See the history through the concrete and real elements along the city allow the citizen to take part of his/ her own citizenship.
\end{abstract}

Keywords: Town planning, History of City, Brazilians Cities, Porto Alegre.

\title{
Cidade, história e urbanismo
}

A ideia de que é possível conferir as marcas que as correntes históricas do urbanismo deixaram ao longo do tempo na cidade levou a se propor alguns procedimentos metodológicos para essa análise. Através da escolha de percursos urbanos, que atravessam vários períodos de tempo, se consegue mostrar como se deu a transformação e a pluralidade do urbanismo da cidade. Sendo a observação um primeiro instante do processo do conhecimento, e que se dá através dos sentidos, da experiência e da percepção, Svensson explicita:

A matéria assim captada é tratada pela razão num processo de comparações e generalizações dos fatos, em busca, através de referências sócio-culturais e históricas, do esclarecimento das leis que regem os fenômenos. O subjetivo e o objetivo surgem assim dentro do 
conhecimento, desde o primeiro instante. O objetivo é reconhecido através da interpretação imaginária do sujeito. ${ }^{1}$

Nesse sentido, um percurso linear pela cidade pode ser entendido como estratégia de reconhecimento e ordenamento da percepção de uma estrutura ambiental definida ${ }^{2}$, para conduzir ao conhecimento.

O deslocamento pelo percurso permite que o indivíduo perceba os diferentes espaços que compóem a cidade, compreenda o porquê de cada parte dela ser como é e entenda as transformações que ela sofreu ao longo do tempo. Propõe-se ainda que sejam percebidas as semelhanças e diferenças de procedimentos de intervenção, através de comparações, não só entre cada um de seus trechos, mas entre percursos e até mesmo entre cidades. $\mathrm{O}$ trajeto que é analisado neste texto corta Porto Alegre de norte a sul. Inicia-se, no Cais do Porto com as avenidas Mauá e Sepúlveda, passa pela Praça da Alfândega até a Rua dos Andradas, percorrendo-a até a Avenida Borges de Medeiros com seus viadutos. Por esta, chega-se ao Arroio Dilúvio e à Avenida Ipiranga e desse ponto segue-se ainda pela Avenida Borges, continuando em direção à zona sul até a Vila Assunção. Para sua análise se faz necessário dividi-lo em trechos menores.

SVENSSON, Frank. Contribuição à Estruturação do $1^{\circ}$ Semestre do Curso de Arquitetura da Faculdade de Engenharia da Universidade de Angola. Mimeo, 1980. $50 \mathrm{p}$.

2 SOUZA, Celia Ferraz de; CABRAL, Gilberto Flores. Percursos Urbanos: a Reconstituição do Cotidiano. In: $1^{\circ}$ Encontro Sobre História Urbana - ANPUR. Salvador, 1990. 

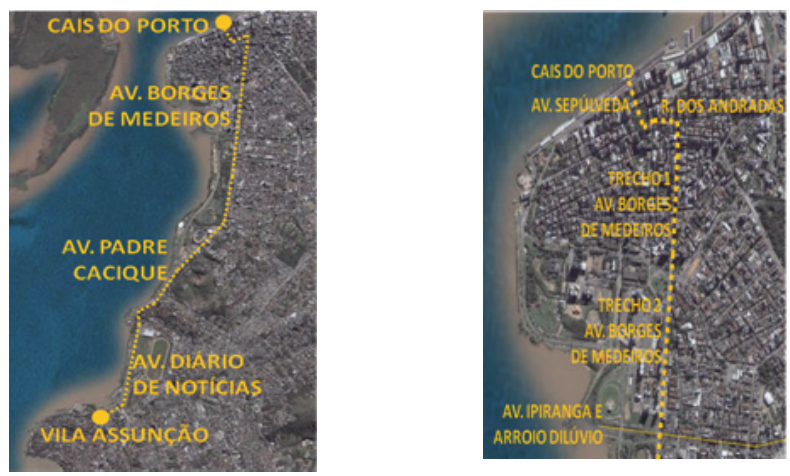

Fig. 1 e 2: Mapeamento do percurso completo sobre imagem de satélite (Google maps).

Um percurso pode ser feito à luz de vários conhecimentos. Neste caso específico, a base está no conhecimento urbanístico e em suas fundamentações.

O porto, a avenida Mauá, a avenida Sepúlveda, a Praça da Alfândega e a rua dos Andradas - do colonial à modernidade.

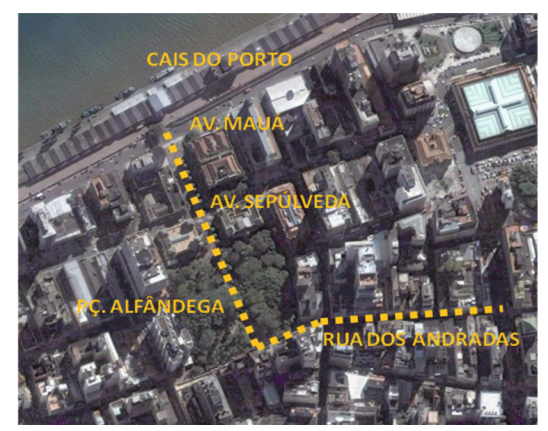

Fig. 3: Mapeamento do trecho 1. 


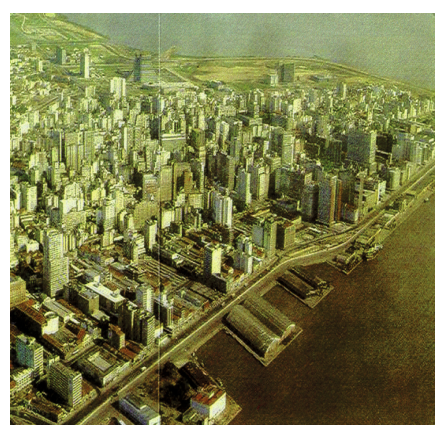

Fig. 4: Vista do centro da cidade com seu porto (Acervo Gedurb).

O Cais está localizado no centro da cidade, fisicamente separado dela por um muro de concreto de 3 metros de altura. O muro faz parte de um sistema de proteção contra as enchentes do Lago Guaíba e foi criado em resposta às inundações, em especial à grande enchente de 1941. Além do muro, os trilhos da linha do TRENSURB (metrô de superfície) contribuem para separar os armazéns do cais do resto de Porto Alegre. Com sua desativação, o Cais Mauá, como é chamado esae trecho, acabou subutilizado, restando em funcionamento o prédio administrativo e o embarque de passeios turísticos pelo Guaíba.

Os armazéns têm sido alugados para os mais diversos eventos. A Avenida Mauá, que acompanha a linha portuária, dividida ao meio pelo muro, e ainda assim, ela, que teria grande potencial para empreendimentos imobiliários devido à sua vista para o lago e para as ilhas, acabou dominada por edifícios-garagem já que a demanda por vagas para estacionamento no centro é enorme, contribuindo para a desvalorização dessa via. Para o sistema viário, entretanto, ela é extremamente importante, conduzindo o fluxo que chega à cidade pela região norte. Forma, com a Rua Siqueira Campos, um binário de retorno. No acesso do porto, junto à Praça da Alfândega, encontram-se importantes edifícios históricos como a Alfândega, a Secretaria da Fazenda, a Delegacia Fiscal e os Correios e Telégrafos. Esses últimos, localizados na esquina com a praça, foram construídos simetricamente, seguindo os moldes do urbanismo barroco (Figs. 6 e 7). 
Essa praça, atualmente, está tomada pelas sombras projetadas pelas grandes copas dos jacarandás, impedindo uma adequada leitura do seu espaço. $\mathrm{O}$ traçado que organiza essa praça foi feito nos moldes dos jardins franceses com canteiros e caminhos simétricos e diagonais. Até hoje, ela abriga a Feira do Livro, que ocorre anualmente, além de pequenas feiras de artesanato permanentes. Essas atividades remetem ao papel de centralidade da praça.

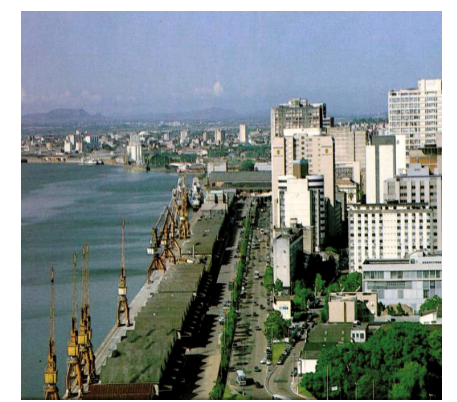

Fig. 5: Av Mauá, o muro, os trilhos, os armazéns e o lago (Acervo Gedurb).

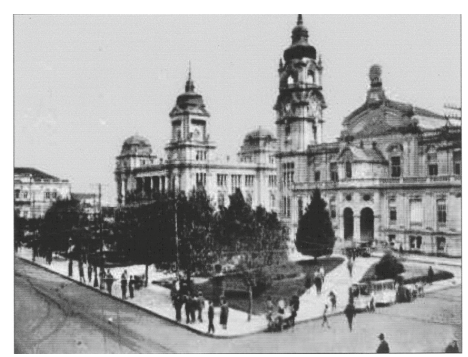

Fig. 6: Praça da Alfândega com os prédios (Acervo Gedurb).

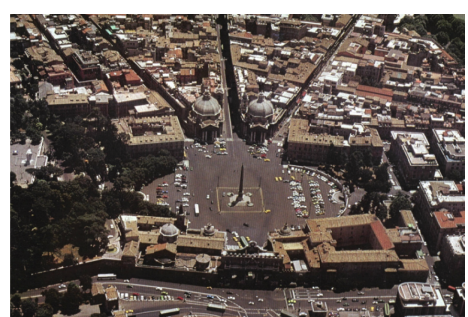

Fig. 7: Urbanismo barroco - Piazza Del Poppolo- Roma (Acervo Gedurb). 
Do ponto de vista urbanístico, o Cais do Porto representa uma área conquistada através de sucessivos aterros, definida pela Avenida Mauá. (Fig. 8) Originalmente, a margem do Lago Guaíba localizava-se na Rua da Praia, a atual Rua dos Andradas. Em meados do século XIX, começou a se estender ao longo da Rua Nova da Praia, que passou a se chamar Rua Sete de Setembro. A construção do cais foi determinante para o acontecimento das reformas empreendidas em Porto Alegre, no século XX, pois foi por causa dele que o Plano de Melhoramentos de 1914 foi elaborado, conduzindo o início da modernização da cidade 3 . Para isso, foi criada a Comissão de Melhoramentos e Embelezamentos, em 1912, cujos princípios para solucionar os problemas existentes eram os mesmos da reforma sofrida em Paris, desde meados do século XIX: sanear, circular e embelezar. O plano atingia as novas áreas conquistadas pelos aterros e tinha, como uma das preocupações adaptar o sistema viário, estendendo e alargando ruas existentes, sanear as áreas inundáveis e alagadiças e embelezar a orla e a cidade com parques e jardins. O Plano, concluído em 1914, sob a organização do engenheiro-arquiteto João Moreira Maciel, além de contar com projetos novos, incorporou também os já existentes(Fig. 9).

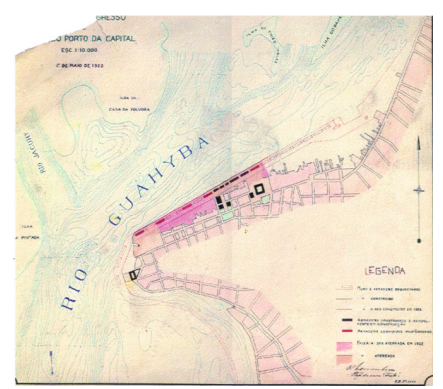

Fig. 8: Evolução dos aterros na margem norte.Estágio das obras de aterros em 1922 (Acervo Gedurb).

3 Ver SOUZA, Celia Ferraz de. Plano Geral de Melhoramentos de Porto Alegre: o Plano que Orientou a Modernização da Cidade. Porto Alegre: Armazém Digital, 


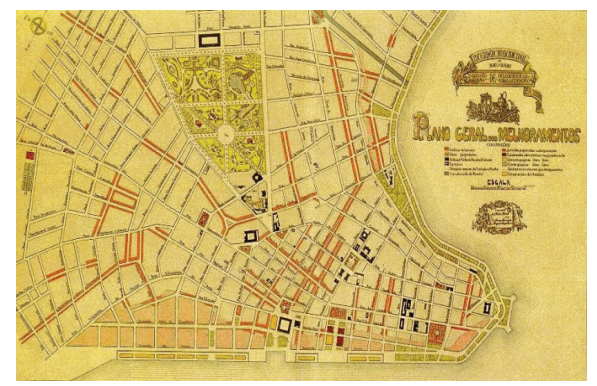

Fig. 9: O Plano de Melhoramentos de 1914.

A Avenida Mauá é uma dessas vias criadas pelo Plano, chamada na época de Avenida do Porto, que deveria se ligar com outra que atravessava um parque, costeando a margem do Guaíba, indo até o bairro Tristeza na zona sul. Já a Avenida Sepúlveda, nasceu de um projeto anterior ao Plano que pretendia ligar o porto ao palácio do governo, no alto da colina, que acabou sendo inviabilizado pelas dificuldades de vencer a topografia e seus altos custos. Assim, apenas parte desse projeto foi implantada, que vai do portão do porto à Praça da Alfândega e Rua da Praia. A Av. Julio de Castilhos, antigo projeto da Rua das Flores, continuação da Rua Siqueira Campos, foi previsto nesse plano como um verdadeiro boulevard. Avenida larga, com canteiro central, iluminação, e propostas para se tornar o novo ponto comercial da cidade, em detrimento da Rua da Praia, assim como a Rua do Ouvidor deu lugar à Avenida Central (Rio Branco), no Rio de Janeiro (Fig.11). Fato que acabou não ocorrendo, apesar de suas marcas urbanísticas terem ficado.

As primeiras remodelações urbanas no Brasil ocorreram no Rio de Janeiro, marcando a então capital, pela obra do engenheiro Pereira Passos, prefeito da cidade. A partir do início do século $\mathrm{XX}$, o Rio passa a servir de modelo para as demais cidades brasileiras. A abertura de avenidas parecidas com a Avenida Central, ou Rio Branco, lembrando um boulevard parisiense, se propagou pelo país. As avenidas começam assim a aparecer em Porto Alegre, em grande contraste com as ruas coloniais. Se realmente a 
mudança trazia semelhanças tais, que iam desde suas dimensões à morfologia e às tipologias arquitetônicas da capital europeia, no caso da capital gaúcha pela sua tardia implantação, acabou não se servindo mais das tipologias arquitetônicas da época inicial e sim da mais atual de então, a arquitetura modernista.

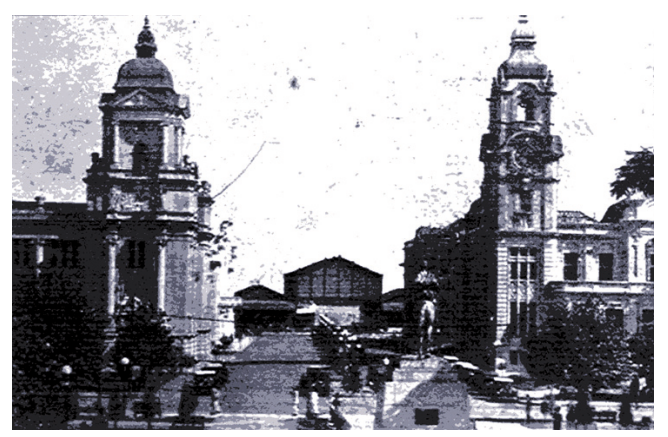

Fig. 10: Vista da Avenida Sepúlveda (Acervo Gedurb).

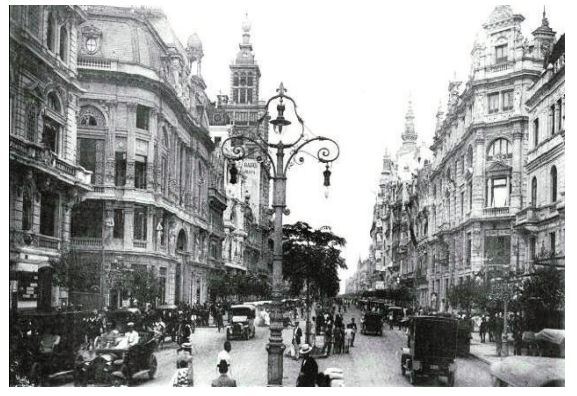

Fig. 11: Av. Central, RJ. 1910 (Acervo Gedurb).

A Rua dos Andradas, ou Rua da Praia, uma das primeiras ruas da cidade, foi por onde circulavam os bondes e carros, e após os anos 1970, tornou-se um grande calçadão para pedestres. Isso se justificava pelo seu grande fluxo durante todo o dia, e a exemplo de outras cidades, passou a se valer desse procedimento urbanístico. A ideia de calçadão surgiu após a segunda guerra, sendo experienciado pela primeira vez em Amsterdam, transformando uma via de circulação de veículos em via pietonal, com quiosques, 
canteiros, etc., diversificando o caminho. Essa proposta passou a ser reproduzida em inúmeras cidades no sentido de facilitar o trânsito. A tipologia arquitetônica foi sendo substituída por grandes edifícios em altura, ao longo de todo seu comprimento, inclusive no entorno da praça.

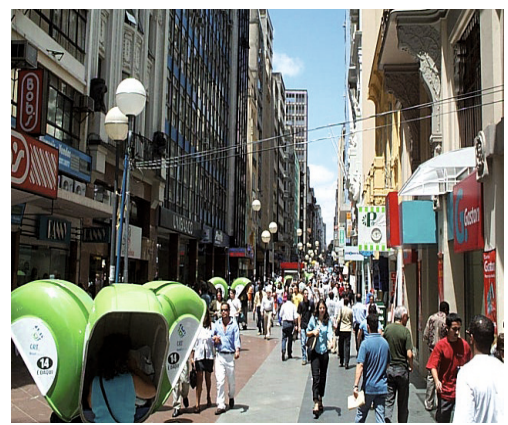

Fig. 12: O calçadão da Rua dos Andradas. 


\section{A primeira etapa da avenida Borges de Medeiros}

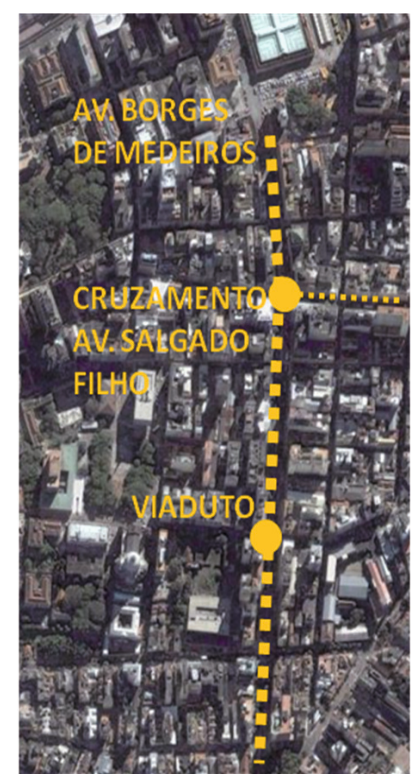

Fig. 13- Mapeamento de trecho 2.

A abertura da Avenida Borges de Medeiros, no trecho compreendido entre a Praça Daltro Filho e o Mercado Publico foi uma decorrência do Plano de Melhoramentos e implantada entre 1924 e 1943. No seu lugar existia a Rua General Paranhos, que se iniciava na Rua Andrade Neves, subia até a Rua Duque de Caxias, no alto do espigão, e continuava descendo em direção ao sul, até a Rua Coronel Genuíno, próximo da desembocadura do Arroio Dilúvio. Um viaduto de concreto armado e arco abatido foi construído com o rebaixamento de 13 metros no ponto culminante por cima do qual dá-se a passagem da Rua Duque de Caxias. O projeto do viaduto foi resultado de um concurso, tendo sido escolhida a proposta do engenheiro Manuel Itaqui e as obras ocorridas entre 1929 e 1932 (Fig.14). Além disso, foi 
feito seu prolongamento em direção ao norte através da abertura pelo meio do quarteirão em uma área extremamente valorizada que incluía parte da Rua da Praia. A intervenção conectou a margem norte com a sul, permitindo a passagem dos bondes de um lado ao outro do centro. A cidade até então não havia nunca visto algo parecido. As dimensões da nova avenida contrastavam com a estrutura da cidade colonial existente. Foi das primeiras avenidas do Centro Histórico que, com seu viaduto monumental e simétrico, tornou-se símbolo da cidade. Hoje, essa avenida encontra-se interrompida ao tráfego de veículos, deixando aos pedestres parte de seu traçado.

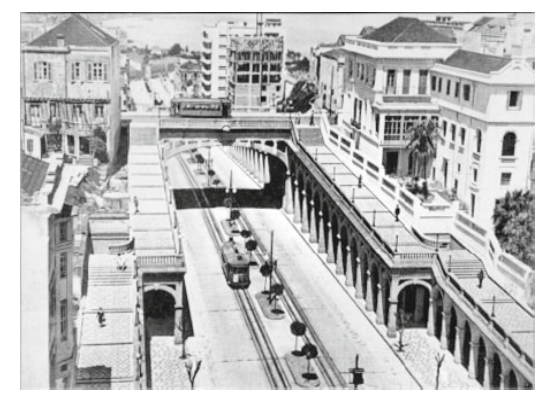

Fig. 14: A Avenida Borges e o Viaduto Otávio Rocha quando de sua inauguração, década de 1930-40.

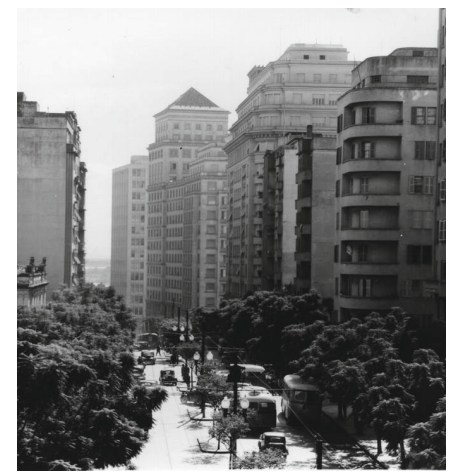

Fig. 15: A Avenida Borges de Medeiros em direção ao Mercado Público, com destaque para o edifício Sulacap e seu telhado de quatro águas. (Acervo Gedurb). 
As características desta via se aproximam muito dos preceitos haussmannianos ${ }^{4}$. Ela funciona como um eixo que conecta as margens norte e sul, possui canteiro central arborizado e equipado com postes de iluminação pública. Além disso, a conexão entre a Borges e a Avenida Salgado Filho, outra avenida proposta pelo Plano de Melhoramentos, deveria constituir o cruzamento central da cidade, a exemplo da grande crevisée $^{5}$, cruzamento de duas vias importantes, utilizada por Haussmann no ponto entre o boulevard Sebastopol e a rue de Rivoli em Paris, acabou não ocorrendo devido à falta do prolongamento, pelo lado da Rua Andrade Neves, da continuidade da Avenida Salgado Filho. As desapropriaçóes feitas para permitir o prolongamento da avenida até a margem norte são também uma característica do urbanismo francês, pois remetem a uma percée, estratégia muito utilizada pelo prefeito parisiense para a abertura dos boulevards. A percée 6 era a passagem de uma avenida pelo meio dos quarteirões, que envolvia a desapropriação e o ressarcimento das perdas aos proprietários. Ela tinha um papel muito importante para o saneamento, pois permitia, acima de tudo, a circulação do ar e a penetração dos raios solares no interior das quadras. Em termos de edificações, em nada ela se parece com um boulevard francês, pois, quando foi implantada, a arquitetura neoclássica e eclética já estavam ficando em desuso. $\mathrm{O}$ movimento modernista crescia, o que resultou em uma serie de edifícios altos, destacando-se entre todos, o Sulacap.

Esse nome decorre do nome do prefeito de Paris, Eugene Haussmann que empreendeu a reforma na cidade-luz.

5 LOUPIAC, Claude. La Ville Entre Represéntations et Réalités. Paris: Scérén, 2005.

6 PINON, Pierre. Atlas Haussmannien. Paris: Parigramme, 2002. 


\section{A segunda etapa da avenida Borges de Medeiros}

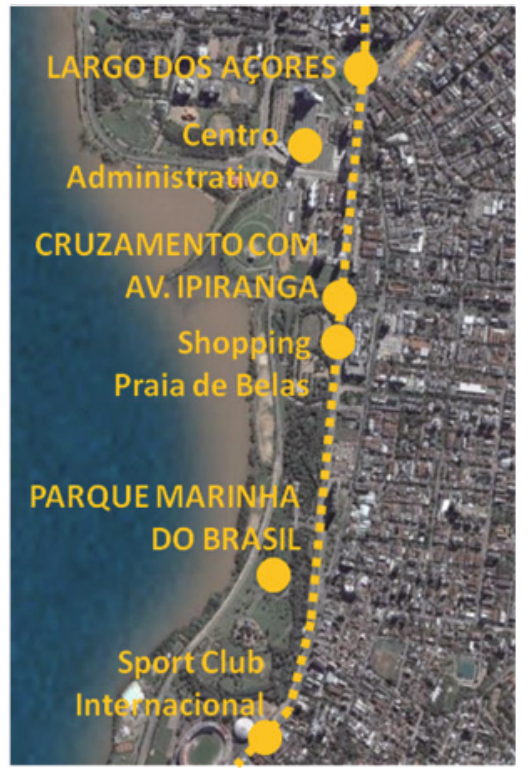

Fig. 16: Mapeamento do trecho 3.

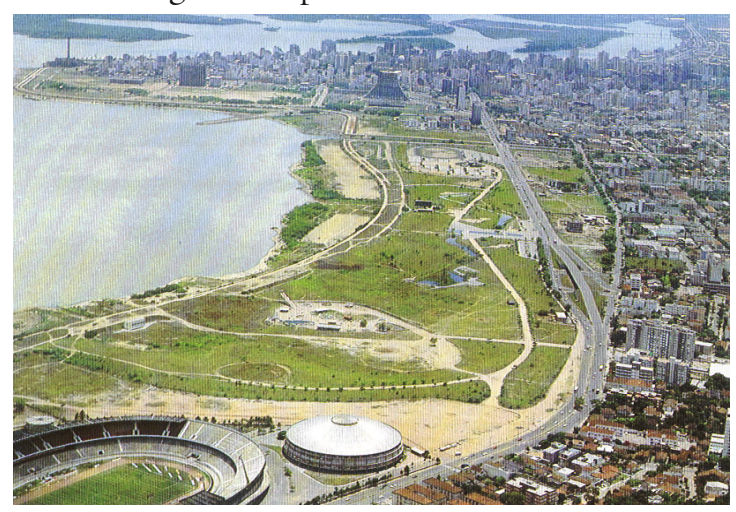

Fig. 17: Vista da Avenida Borges de Medeiros à direita e da Edvaldo P. Paiva à esquerda, o parque entre elas e o estádio do Internacional (Acervo Gedurb). 
Esta segunda etapa da Avenida Borges de Medeiros, ao sul do Centro de Porto Alegre, está situado em uma grande área de aterros e foi implantado entre 1970 e 1989. A avenida percorre aqui um longo caminho, acompanhada por um importante parque da cidade: o Parque Marinha do Brasil. Além disso, nessa região, foi implantada uma série de equipamentos de porte, como edifícios institucionais do Centro Administrativo do Estado do Rio Grande do Sul e edifícios residenciais, no seu início. No cruzamento com a Avenida Ipiranga e seu riacho, fica o Shopping Praia de Belas, hotéis e edifícios do judiciário. Prosseguindo, encontra-se o complexo do Sport Club Internacional, no ponto em que já passa a se chamar Avenida Padre Cacique. Paralelamente à Borges, do outro lado do parque, tem-se a Avenida Edvaldo Pereira Paiva, reproduzindo a ideia do Plano de 1914, que previa uma via com um parque no seu entorno para chegar até a Tristeza, o que lembra propostas de Saturnino de Brito, particularmente para o plano de Santos ( Figura 17). Essa via até hoje funciona de forma incompleta, com apenas uma pista, embora sua permanência tenha sido reforçada nos planos que se seguiram: o Plano Gladosch (1939), o Plano de Loureiro da Silva (1943), o $1^{\circ}$ Plano Diretor (1959) e o $1^{\circ}$. Plano de Desenvolvimento Urbano, de 1979. Assim como a Borges, a Avenida Edvaldo Pereira Paiva conecta o Centro com a Zona Sul. O prolongamento dela também estava previsto no Plano de 1914, porém com outro nome: Avenida Piratiny. Essa avenida, no plano, fazia uma inflexão no seu curso, no ponto onde hoje se tem o cruzamento com a $1^{\text {a }}$ Avenida Perimetral, a Avenida Loureiro da Silva, no Largo dos Açorianos. Com os aterros da Praia de Belas, essa inflexão tornou-se desnecessária e a Avenida Borges pode seguir em linha reta, passando por cima dela dois viadutos de concreto, se integrando à paisagem modernista que se criava. Essa continuação acabou por se tornar diretriz da orla, do parque e do traçado das novas vias abertas nessa área.

Morfologicamente, este trecho se difere completamente do anterior devido a sua implantação com edifícios afastados uns dos 
outros e vias de trânsito rápido, dando prioridade aos automóveis, assim como a Edvaldo P. Paiva, pensada como via expressa. As referências teóricas desse tipo de propostas podem ser remetidas a projetos modernistas, como os de Le Corbusier, de 1935, para o plano Voisin, como mostra a Figura 18, ou nos planos de Robert Moses, nos anos 60 para Nova York, que implantou uma série de vias expressas ligando Manhattan aos outros bairros da cidade, especialmente o do Bronx, tão bem descrito e analisado por Marshal Berman, no seu Tudo que é sólido se desmancha no ar. O movimento modernista, funcionalista racionalista, ocorre a partir do século $\mathrm{XX}$, visando criar uma ruptura ao existente. A cidade deveria conter altas densidades populacionais, porém, com espaços também generosos, no sentido do que dizia Le Corbusier, um dos próceres desta corrente: "concentrar para descongestionar". Ou seja, edifícios altos e liberação do solo. Além disso, seus protagonistas pregavam a geometrização do traçado, com vias largas expressas atendendo a uma hierarquia de tráfego. A organização da cidade através de suas funções era o ponto fundamental de suas propostas. Habitar, trabalhar, recrear e circular eram as categorias funcionais pelas quais a cidade definiria sua estrutura espacial. Pensando dessa maneira, seria difícil implantar essas ideias na cidade existente, pois tratavam o projeto em termos de "távola rasa".

Entretanto, como as cidades novas não eram solicitadas com frequência, a ideia viável foi entrar nas cidades com suas largas vias, nem sempre tão expressas como pregavam seus propositores, e organizações funcionais. Muitas foram as cidades transformadas por esse processo, como a própria Paris dos anos 70 do século XX, para ficar num exemplo só. 


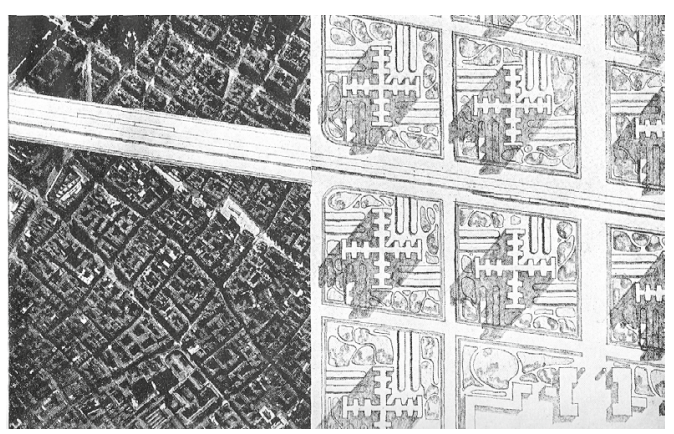

Fig. 18: Comparação de escalas do Plan Voisin, de Le Corbusier, para Paris com a avenida expressa de acesso: à esquerda o tecido existente, à direita a proposta de intervenção (Acervo Gedurb).

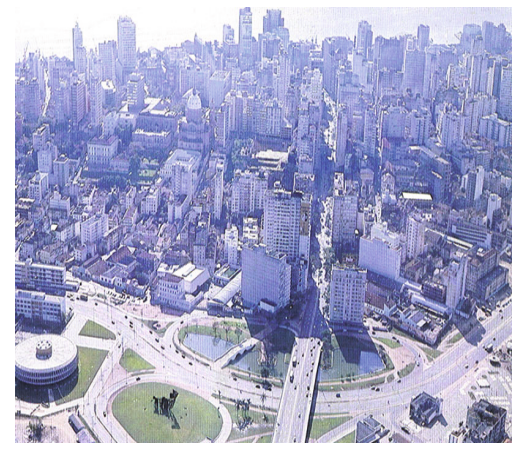

Fig. 19: Largo dos Açorianos (Acervo Gedurb).

A repercussão do movimento modernista, ou racionalista funcionalista, nas cidades brasileiras aparece inicialmente através da arquitetura das edificações em altura, já que em termos urbanísticos, seus princípios de começar a construção da cidade a partir do zero, invalidavam sua aplicação. Apesar disso, a cidade foi se transformando pelo princípio da substituição, destruir e construir, levando as antigas ruas coloniais ou avenidas recémabertas a construir edifícios em altura, especialmente nos centros, modificando a paisagem existente, ou ainda pelos critérios do novo zoneamento, pregado pela Carta de Atenas, que acabou por retirar dos centros das cidades a função habitação, deixando-os à noite isolados e vazios. 
A Avenida Presidente Vargas, proposta pelo urbanista Alfred Agache, no Rio de Janeiro em 1930, e implantada durante o Estado Novo, já poderia ser vista como um prenúncio desse movimento, por suas dimensões e usos. Entretanto, as vias expressas características dessa corrente, a partir do final dos anos 1960, vão começar a aparecer nas cidades, adaptando as propostas teóricas iniciais que não as previam dessa forma. $\mathrm{O}$ resultado do crescimento da indústria automobilística, que potencializou o número de carros circulando pelas ruas, obrigou as municipalidades a tomarem providências no sentido de aumentar a largura e as extensões das mesmas, de forma que os veículos tivessem espaços exclusivos, independentemente dos pedestres. $\mathrm{O}$ aproveitamento de estudos mais recentes a esse respeito contribuiu para uma modernização forçada. Foram abertas perimetrais, marginais, radiais, eixos, enfim, tudo para facilitar a circulação mais rápida, o que provocou mais uma grande ruptura na cidade existente.

\section{A avenida Ipiranga e o arroio Dilúvio}

O riacho tem sua nascente na represa da Lomba do Sabão, zona leste de Porto Alegre, e corria mais ou menos paralelamente à estrada do Mato Grosso (atual avenida Bento Gonçalves), que ligava Porto Alegre a Viamão. Vinha com o nome de Arroio Dilúvio, e continuava com o nome de Arroio da Azenha até um lugar chamado Ilhota (onde havia a confluência com o Arroio Cascatinha). Daí seguia com o nome de Riacho, ou Riachinho, e, de forma sinuosa, na altura da Avenida João Alfredo desviava-se para a direita, percorrendo um trajeto de 2.900 metros até desaguar no Lago Guaíba ${ }^{7}$.

SOUZA, Celia Ferraz de. Plano Geral de Melhoramentos de Porto Alegre: o Plano que Orientou a Modernização da Cidade. Porto Alegre: Armazém Digital, 2008. 232 . 


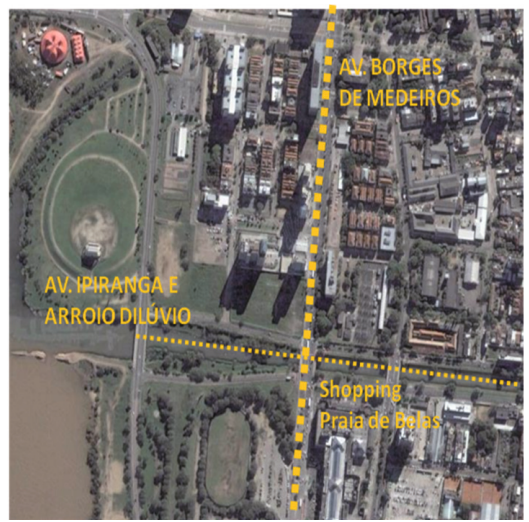

Fig. 20: Mapeamento do trecho 4.

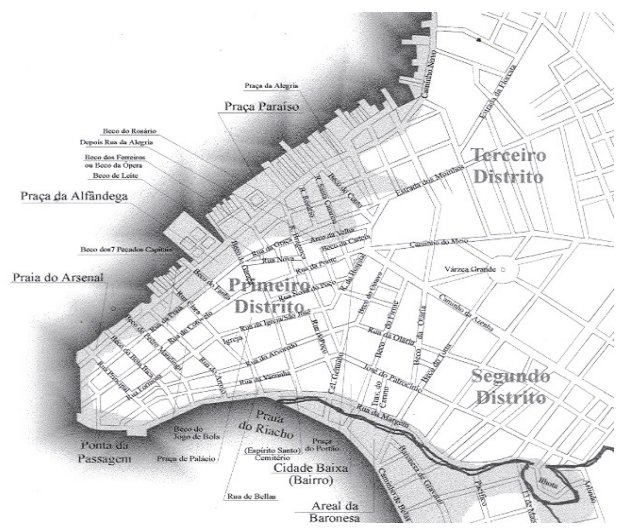

Fig. 21: Planta de 1916. Na parte baixa da imagem, o traçado original do Arroio Dilúvio, mostrando a Ilhota, formada também com seu afluente Cascatinha, e na hachura cinza, a indicação das áreas alagadas pelas enchentes. Desenho sobre a planta - autora (Acervo Gedurb).

As obras de canalização do Arroio Dilúvio eram extremamente necessárias, pois esse arroio provocava uma série de problemas de saneamento devido às suas enchentes, especialmente na área da Ilhota. A ideia de canalização e retificação vem do final do século XIX. No Plano de Melhoramentos ele assim aparece, mas isso realmente só foi acontecer na década de 1950. Sua retificação e canalização seguiram os ideais higienistas do urbanismo 
moderno, promovendo o fim das inundações. Já a construção da Avenida Ipiranga, implantada ao longo das margens do arroio, obedece bem mais às características do urbanismo modernista. A larga avenida passou a ser uma importantíssima via de integração, cruzando vários bairros e facilitando o deslocamento entre diversas regióes. Aproximando a zona norte da zona sul, a área foi sendo ocupada, porém sem nenhuma regulamentação, para com sua integração com os tecidos viários vizinhos, o que se mostra até hoje como um problema de adequação de níveis. Houve um crescimento populacional na região que trouxe em contrapartida, o problema da preservação do Riacho canalizado. Hoje, mesmo depois de inúmeros planos para sua recuperação e limpeza, ele representa uma área de grande problema para a questão do meio ambiente.

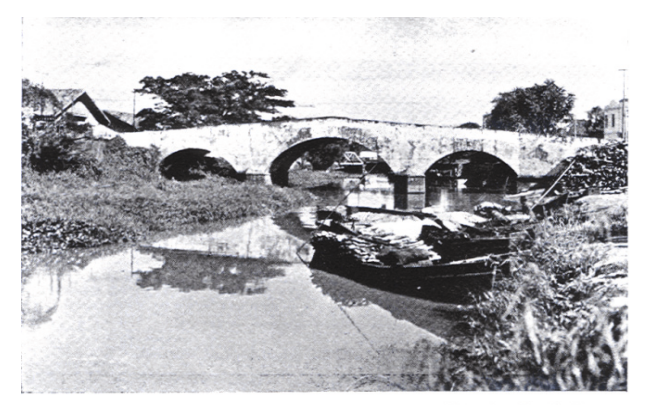

Fig. 22: Imagem de antes da canalização do Arroio Dilúvio quando ele ainda passava pela antiga Ponte de Pedra (Acervo Gedurb).

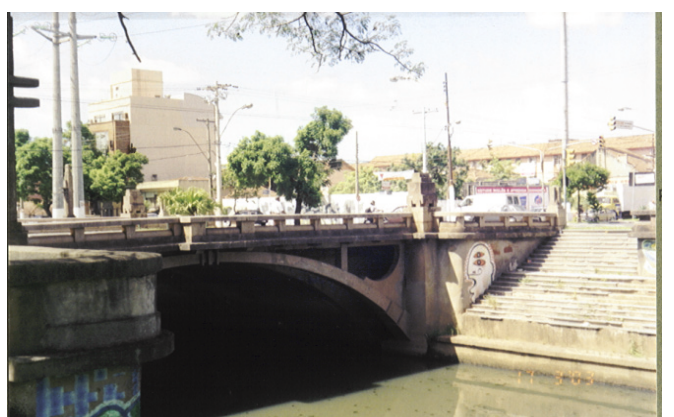

Fig. 23: Imagem atual, canalizado com pontes atravessando seu leito (Acervo Gedurb). 


\section{Do Internacional à vila Assunção}

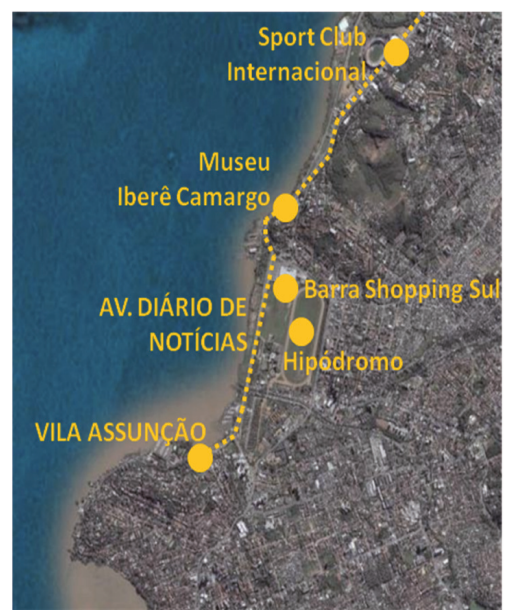

Fig. 24: Mapeamento do trecho

O bairro Vila Assunção, projetado pelo engenheiro Ruy de Viveiro Leiria em 1937, está localizado na Zona Sul de Porto Alegre, à beira do Lago Guaíba, implantado em uma área acidentada que pertencia originalmente ao bairro Tristeza. $\mathrm{O}$ caminho até esse ponto passa pelo novo Museu da Fundação Iberê Camargo, obra do arquiteto português Álvaro Siza, e pelo novo Barra Shopping Sul, próximo ao Hipódromo de Porto Alegre, através da Avenida Diário de Notícias que se abre aqui em três pistas de cada lado com largos canteiros no seu centro.

A Vila Assunção possui características típicas da cidadejardim. Basicamente residencial, a tipologia arquitetônica predominante é a da habitação unifamiliar, com algumas exceções, já que parte de sua orla, atualmente, acabou sendo ocupada por habitações irregulares, que hoje já se integraram ao contexto geral. Seu projeto é caracterizado por baixas densidades e pelo aproveitamento das condições topográficas do terreno, resultando em um traçado orgânico. As ruas foram projetadas levando em consideração a direção dos ventos predominantes, garantindo 
aos lotes e prédios boa aeração e iluminação. Nas partes menos acidentadas, foi projetada uma série de quadras alongadas providas de caminhos para pedestres e algumas áreas de lazer. Essas áreas, localizadas nos fundos dos lotes buscam formar recantos conectados com as vias por caminhos ajardinados. As ruas contêm entre a pista e os passeios duas faixas gramadas onde são plantadas árvores de sombra. A testada mínima adotada é de 12 metros e a profundidade mínima é de 40 metros.

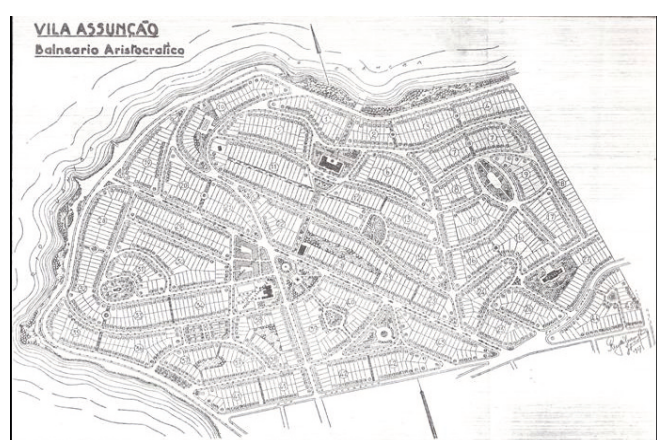

Fig. 25: Planta do bairro Vila Assunção (Acervo Gedurb).

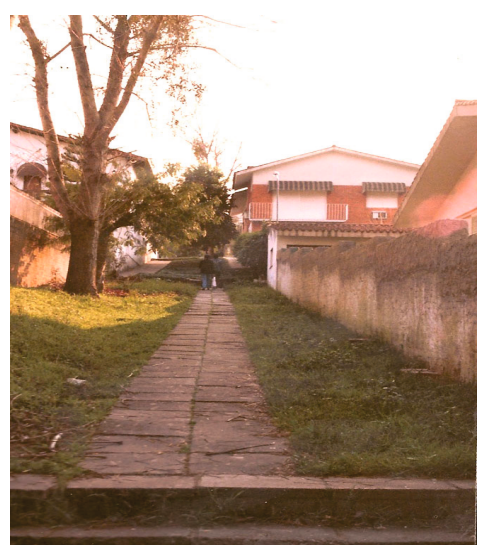

Fig. 26: Caminho de pedestres pelo interior de quarteirão da Vila Assunção (Acervo Gedurb). 
A casa deveria ocupar de 25 a $35 \%$ do lote, com afastamentos laterais e frontais obrigatórios, sendo preferível que ela ficasse no meio do lote. Há também um zoneamento quanto ao comércio, localizando-o em um único ponto central do bairro. Os caminhos de pedestres atravessam as quadras, encurtam o caminho e criam ambientes pitorescos, como queria o arquiteto vienense, Camilo Sitte, um dos próceres dessa corrente, já no final do século XIX.

De acordo com relatório do autor ${ }^{8}$, duas escolas foram projetadas em meio a praças, cuja acessibilidade gira em torno de 700 metros, característica que pode ser associada ao conceito de unidade de vizinhança. Segundo o mesmo texto, os melhoramentos da orla e os ajardinamentos foram inspirados em praias uruguaias, tais como Pocitos, Malvin e Carrasco, que decorrem também do urbanismo de cidade-jardim ou culturalista de maneira geral.

O movimento das cidades-jardim ocorreu entre o fim do século XIX e as primeiras décadas do século XX, sendo sua aplicação feita com grande intensidade após a segunda guerra mundial. Na realidade, o berço desta corrente surgiu com Ebenezer Howard, teórico inglês, que se preocupava com as condiçóes deficitárias de vida dos operários e com a especulação do solo urbano. Ele propôs um modelo de cidade que serviria de base para arquitetos onde procurava evitar os problemas recorrentes da época. A cidade deveria ser autossuficiente, apresentar uma integração completa com o campo, formando um terceiro pólo de atração; o solo deveria pertencer à comunidade, e as indústrias não deviam ser poluidoras. A implantação desse modelo teórico acabou se tornando o verdadeiro modelo dessa corrente. Raymond Unwin e Barry Parker construíram a primeira cidadejardim, Letchworth, trazendo novas características morfológicas e tipológicas, modificando significativamente a paisagem da cidade

LEIRIA, Ruy de Viveiro. Projeto de Urbanização da Vila Assunção. In: Boletim da Sociedade de Engenharia. Sociedade de Engenharia do Rio Grande do Sul. 1940, no 31. Porto Alegre: Sociedade de Engenharia, 1937. 
e principalmente das áreas residenciais. Posteriormente esse pensamento foi incrementado pela corrente culturalista dos anos 30 do século XX, na implantação de Radburn, subúrbio de Nova York. A proposta era de que a cidade tivesse como unidades não os lotes, mas a vizinhança. A unidade de vizinhança congregaria a área de habitação, a escola e os serviços básicos, abrangendo um raio de $400 \mathrm{~m}$, distância que uma criança poderia caminhar tranquilamente. Propugnava traçado orgânico, que acompanhasse as curvas de nível do terreno e achavam que o urbanismo nunca deveria romper com a linha de evolução cultural da cidade, portanto, deveria se ajustar ao existente, "curar a cidade doente".

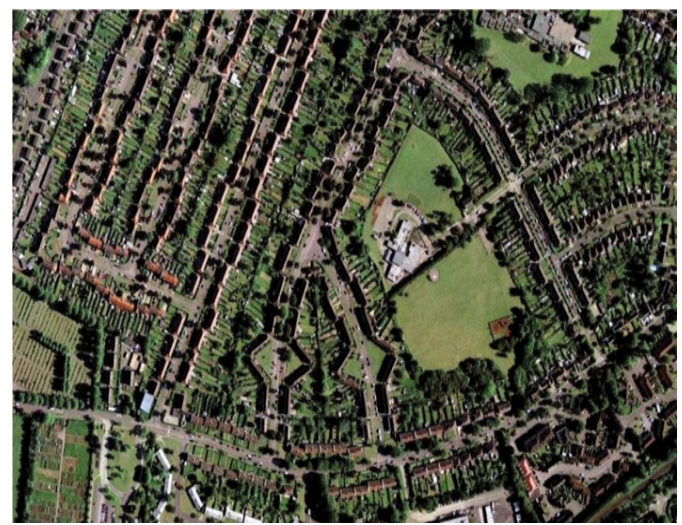

Fig. 27: Vista de Letchworth, primeira cidade-jardim, Inglaterra.

No Brasil na mesma época, em que se abre a Avenida Central no Rio, com as características do urbanismo francês, se vê a abertura da Avenida Paulista, em São Paulo, mostrando uma configuração espacial completamente diferente. Em vez de uma rua corredor, com prédios uniformes de habitação coletiva e comércio no térreo unidos lateralmente delimitando seu espaço, característica até então das ruas urbanas, se encontram palacetes, unifamiliares, de estilos variados, afastadas dos limites do lote, ocupando os espaços livres com jardins, lembrando mais as ideias de cidades-jardim, implantadas na Inglaterra. 


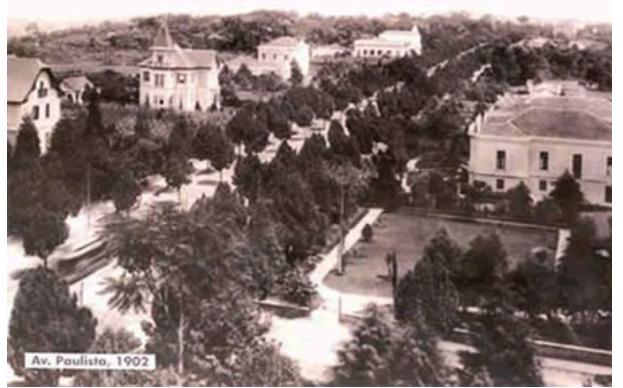

Fig. 28: Vista da Avenida Paulista (Acervo Gedurb).

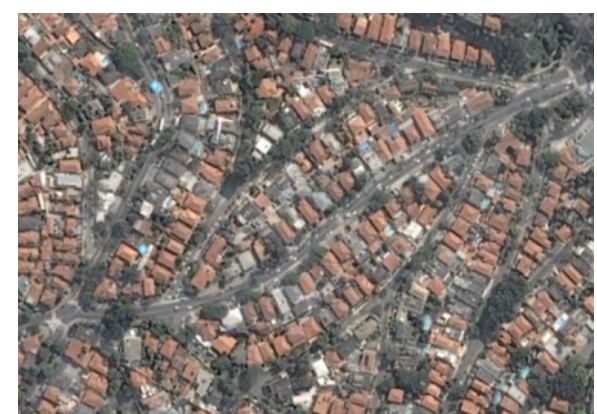

Fig. 29: Vista aérea do bairro Jardim América (Acervo Gedurb).

No entanto, essas ideias passam a ficar mais claras quando é implantado o novo bairro em São Paulo, o Jardim América, projetado pelo próprio Berry Parker, em 1916, que juntamente com Unwin havia projetado Letchworth, a primeira cidade-jardim da Inglaterra. Essa proposta teve uma enorme ressonância pelas cidades brasileiras, através de bairros jardim. Exemplos desse tipo se encontram em Porto Alegre, no bairro Vila Assunção, na Vila do IAPI ou na Vila Conceição. 


\section{Observações finais}

O reconhecimento e a visualização de elementos urbanísticos nesta rápida análise sobre Porto Alegre pode dar uma ideia de quanto é importante mostrar a pluralidade de seus papeis nas cidades, nas marcas deixadas na estrutura urbana, através do tempo e suas origens.

O percurso piloto feito sobre Porto Alegre possibilitou, não só identificar a cidade do urbanismo plural, como também a utilização de um método de leitura urbana que permite reconhecer inclusive formas e presenças de práticas sociais que se manifestam ao longo de sua história.

Novas categorias de análise, como, por exemplo, a historia dos lugares, biografias dos atores e autores, testemunhos e perspectivas trariam um avanço para a própria análise da evolução urbana. ${ }^{9}$ A cidade do urbanismo plural pode, assim, revelar, e mostrar toda a gama de ressonâncias urbanísticas, problemas e temas que a envolvem na trajetória de sua história urbana. $\mathrm{E}$ mais, permitir um avanço na perspectiva de novas categorias de análise dentro da orientação dos percursos urbanos.

\section{Referências}

BERMAN, Marshall. Tudo que é sólido se desmancha no ar: a aventura da modernidade. São Paulo: Cia das Letras, 1987.

LEIRIA, Ruy de Viveiro. Projeto de Urbanização da Vila Assunção. In: Boletim da Sociedade de Engenharia. Sociedade de Engenharia do Rio Grande do Sul. 1940, n. 31. Porto Alegre: Sociedade de Engenharia, 1937.

LOUPIAC, Claude. La Ville Entre Represéntations et Réalités. Paris: Scérén, 2005.

O uso de ferramentas apropriadas fornecidas pela informática pode auxiliar na exposição de um Atlas virtual, que viria se tornar muito interessante pela dinâmica de acesso rápido às informaçốes pelo uso de links e outros meios. 
PINON, Pierre. Atlas Haussmannien. Paris: Parigramme, 2002.

SOUZA, Celia Ferraz de; CABRAL, Gilberto Flores. Percursos Urbanos: a Reconstituição do Cotidiano. In: $1^{\circ}$ Encontro Sobre História Urbana ANPUR. Salvador, 1990.

SOUZA, Celia Ferraz de. Plano Geral de Melhoramentos de Porto Alegre: o Plano que Orientou a Modernização da Cidade. Porto Alegre: Armazém Digital, 2008.

SOUZA, Celia Ferraz de; MULLER, Dóris Maria. Porto Alegre e Sua Evolução Urbana. Porto Alegre: UFRGS, 2007.

SOUZA, Celia Ferraz de. Trajetórias do Urbanismo em Porto Alegre: 1900-1945. In: LEME, Maria Cristina da Silva (Org.). O Urbanismo no Brasil: 1895-1965. São Paulo: Studio Nobel, 1999.

SVENSSON, Frank. Contribuição à Estruturação do $1^{\circ}$ Semestre do Curso de Arquitetura da Faculdade de Engenharia da Universidade de Angola. Mimeo, 1980. 